\title{
MANIFESTAÇÕES PATOLÓGICAS EM ESTAÇÕES DE TRATAMENTO DE ÁGUA E RECOMENDAÇÕES DE TRATAMENTO E PREVENÇÃO: UM ESTUDO DE CASO NA REGIÃO SUL DO BRAŞIL
}

\author{
FONTANA, PATRICIA \\ Professora \\ Centro Universitário Curitiba (Unicuritiba) \\ Paraná; Brasil \\ patricia.fontana@globo.com
}

\author{
MOREIRA, AMACIN RODRIGUES \\ Professor \\ Universidade Tecnológica Federal do Paraná \\ (UTFPR) \\ Paraná; Brasil \\ amacinrm@utfpr.edu.br
}

\section{RESUMO}

Estações de tratamento de água (ETA) são construções diferenciadas, por serem compostas, usualmente, por grandes elementos estruturais. Ainda, nesse tipo de construção devem ser realizados detalhamentos adequados da estrutura, a fim de compatibilizar a mesma aos esforços decorrentes dos efeitos térmicos, da água e da geometria diferenciada, na qual, usualmente, observa-se a presença de aberturas nos elementos estruturais, a fim de permitir o adequado funcionamento da estação.

Nesse sentido, o presente artigo apresenta o estudo de caso de uma estação de tratamento executada na região sul do país, na qual foi observada a presença de fissuras e trincas decorrentes de falhas de detalhamento da estrutura em concreto armado. Para essa edificação, são apresentados os problemas observados, o diagnóstico, assim como, as recomendações de tratamento e as considerações sobre o detalhamento da estrutura que poderiam ter prevenido o surgimento das manifestações patológicas observadas.

Palavras-chave: concreto armado, ETA, fissuras, recuperação estrutural.

\begin{abstract}
Water Treatment Plants (WTP) are differentiated constructions, as they are usually composed of large structural elements. Also, in this type of construction, adequate details of the structure must be performed in order to make it compatible with the efforts from the thermal effects and from water action, associated with the different geometry, in which, usually, the presence of openings in the structural elements are observed.

In this context, this article presents the case study of a treatment plant executed in the southern region of the country, in which it was observed the presence of cracks resulting from failure to detail the reinforced concrete structure. For this construction, the observed problems and the diagnosis are presented, as well, the treatment recommendations for the structure and the considerations about the structure detailing that could have prevented the occurrences.
\end{abstract}

Keywords: reinforced concrete, water treatment plant, cracks, construction repair.

\section{INTRODUÇÃO}

Uma das etapas iniciais do saneamento básico é o tratamento da água, que consiste em tornar a água potável e própria para o consumo da população. Essa etapa ocorre, usualmente, nas chamadas Estações de Tratamento de Água, que tratase de um local composto por diversos reservatórios que, em conjunto com a utilização de produtos químicos e processos mecânicos, permite o adequado tratamento da água.

As etapas que compõem o tratamento da água são as descritas a seguir, sendo apresentados, brevemente, os conceitos de acordo com Pádua (2006).

Coagulação: Consiste na adição de coagulante (substância química) a fim de facilitar o aumento do tamanho das mesmas na etapa de floculação.

- Floculação: Processo mecânico de agitação da água com o objetivo de promover o contato entre as impurezas e, assim, aumentar o tamanho das mesmas.

- Decantação: Passagem da água por tanques, nos quais ocorre a sedimentação dos sólidos no fundo.

- Filtragem: Remoção de material particulado presente na água, fazendo-a passar por um leito contendo meio granular ou membranas com pequenas aberturas. 
- Desinfecção: Etapa para permitir a inativação de microorganismos patogênicos presentes na água. Usualmente, para tal a água recebe adição de cloro, ozônio ou dióxido de cloro.

- Fluoretação: Adição de compostos contendo o íon fluoreto com a finalidade de combater a cárie infantil.

Portanto, observa-se que os reservatórios que compõem uma estação de tratamento de água (ETA) estão em constante contato com a água e, em algumas etapas, com produtos químicos. Dessa forma, o sistema construtivo mais adotado para a execução desse tipo de sistema consiste no concreto armado, considerado um material de maior resistência às agressividades do ambiente.

No entanto, apesar do concreto ser considerado um material eficiente para essas situações, é essencial que o projeto e a execução sejam elaborados com elevado nível de detalhamento e qualidade a fim de evitar o surgimento de anomalias e falhas, como fissurações, trincas, desplacamentos, entre outras, que podem comprometer o bom funcionamento do sistema.

Com o intuito de orientar os profissionais da área sobre o comportamento das estruturas de concreto armado aplicáveis à Estações de Tratamento de Água, o presente artigo apresenta o estudo de caso de uma ETA localizada em uma região litorânea no sul do país, na qual foi identificada a presença de manifestações patológicas decorrentes de falhas de projeto e executivas, descrevendo as anomalias encontradas, os correspondentes diagnósticos, assim como, recomendações de ações preeventivas a serem tomadas a fim de minimizar o sirgimentos dos problemas observados em novas construções.

\section{DADOS DA OBRA}

Como etapa inicial de levantamento de subsídios para estudo da ETA em análise, foi identificada a localização da mesma e obtidas informações sobre os dados climáticos da região.

A construção encontra-se distante do mar, sendo que aproximadamente 17,5 km separam a ETA do ponto mais próximo com água do mar. A edificação se encontra implantada em uma região não urbana, sem indícios de forte poluição urbana ou industrial.

Em análise do clima da região, observou-se a presença constante de chuva na cidade, sendo classificada como uma região bastante úmida, chegando a valores de umidade do ar de $99 \%$, e temperatura com variações de $13^{\circ} \mathrm{C}$ à $31^{\circ} \mathrm{C}$, com uma média de $20,5^{\circ} \mathrm{C}$. Para obtenção desses dados foram utilizados os gráficos disponibilizados pelo INMET (Instituto Nacional de Meteorologia) e pelo IAPAR (Instituto Agronômico do Paraná), se tratando de fontes oficiais de informações e gratuira.
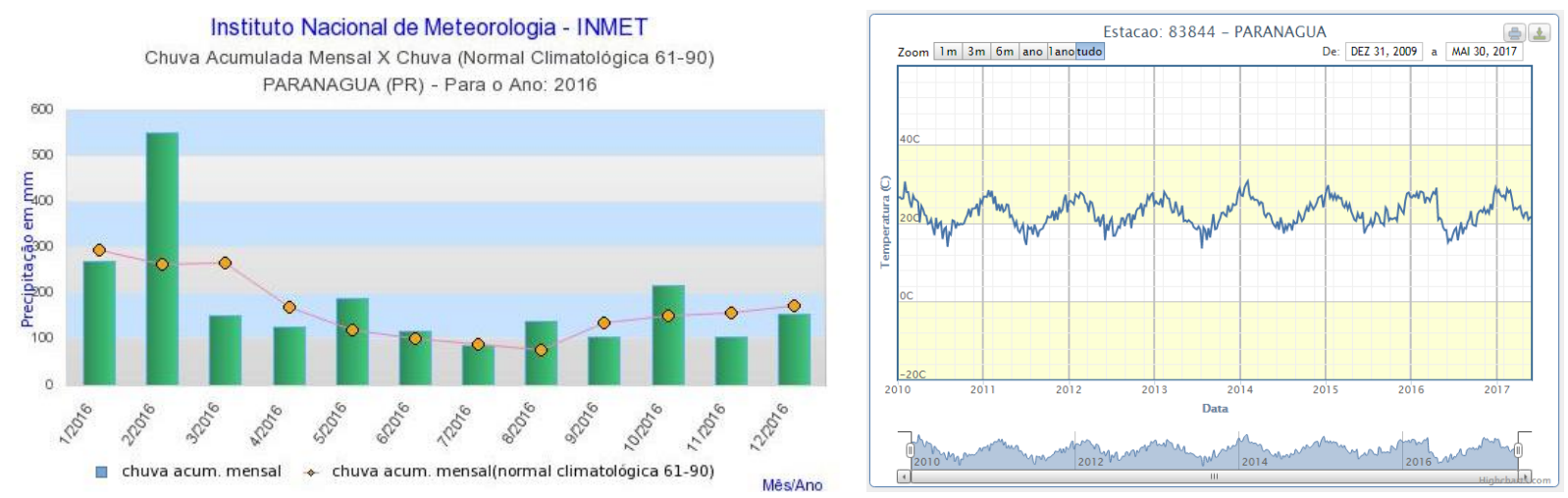

Figura 1: Gráfico Chuva Acumulada Mensal X Chuva no ano de 2016, à esquerda, e Gráfico da umidade da cidade entre os anos 2010 e 2017, à direita.

Fonte: INMET. 
Temperatura Média - Anual

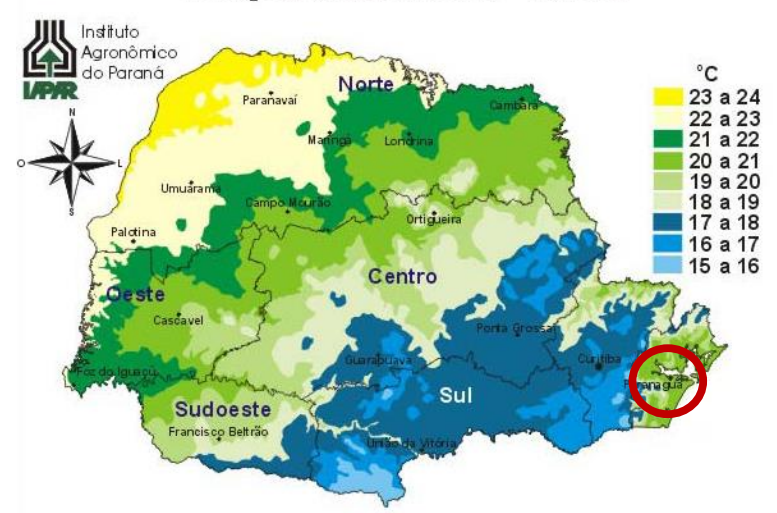

Figura 2: Gráfico das temperaturas do estado do Paraná, entre os anos 2010 e 2017, com destaque para a região litorânea onde a ETA se encontra implantada.

Fonte: IAPAR.

Apesar da construção estar localizanda em uma região urbana, o que classificaria a obra na classe de agressividade ambiental II da norma de projeto de estruturas de concreto armado, a ABNT NBR 6118/2014, a observância de grandes percentuais de umidade e de precipitação de chuvas, aliado ao uso da edificação como Estação de Tratamento de Água, indica que sejam considerados para a obra os critérios da classe de agressividade IV pois, segundo apresentado nas notas da tabela 7.2 da referida norma, "nas superfícies expostas a ambientes agressivos, como reservatórios, estações de tratamento de água e esgoto, condutos de esgoto, canaletas de efluentes e outras obras em ambientes química e intensamente agressivos, devem ser atendidos os cobrimentos da classe de agressividade IV."

Outras informações importantes foram coletadas com a realização de ensaios, como o ensaio de detecção de armaduras, ensaio de carbonatação e de esclerometria.

O ensaio de detecção de armaduras utiliza um localizador eletrônico de barras metálicas em concretos que determina a profundidade e a posição das armaduras. $\mathrm{O}$ ensaio consiste em passar o equipamento na superfície dos elementos estruturais, sendo apresentadas no visor as informações acima descritas sobre as armaduras.

Na obra em análise, o ensaio foi realizado nos pilares e nas paredes, para verificação da posição das armaduras e confirmação do cobrimento adotado na estrutura. Com a realização do ensaio foram obtidas respostas variadas no que diz respeito ao cobrimento das armaduras, sendo identificado que nos pilares e em algumas paredes foram observados cobrimentos da ordem de 2 a $3 \mathrm{~cm}$, valores esses inferiores aos recomendados pela norma para estruturas de estações de tratamento de água, que seria de $5 \mathrm{~cm}$. Ainda, em outras paredes foram observados valores de cobrimento superiores a $6 \mathrm{~cm}$, sendo identificado, ainda, armaduras muito espaçadas.

O ensaio de carbonatação tem por objetivo determinar a presença e a profundidade de carbonatação do concreto, processo esse relacionado com a corrosão das armaduras. A carbonatação é causada pelo agente agressivo $\mathrm{CO}_{2}$ que em condições normais de exposição penetra no concreto e reage com o hidróxido de cálcio diminuindo o pH para valores abaixo de 10. A carbonatação não é prejudicial ao concreto, mas, sob essa nova alcalinidade, a proteção da armadura é destruída e, em presença de umidade e oxigênio, dá-se inicio à corrosão.

A carbonatação do concreto geralmente é uma condição determinante para o início da corrosão das armaduras. Tão logo a frente de carbonatação atinge a espessura correspondente ao cobrimento do aço, começa a despassivação e tem início a oxidação.

O ensaio é realizado com a aplicação de fenolftaleína na superfície analisada. Essa substância mantém-se incolor em soluções ácidas e torna-se cor-de-rosa em soluções básicas. A sua cor muda a valores entre pH 8,2 e pH 9,8. Dessa forma, pode-se verificar a profundidade da carbonatação e então determinar a qualidade da estrutura, principalmente com relação às condições das armaduras. 


\section{MANIFESTAÇÕES PATOLÓGICAS NA ESTAÇÃo DE TRATAMENTO DE ÁGUA}

Segundo apresentado por Metha e Monteiro (1994), as causas de deterioração do concreto são divididas em causas físicas e causas químicas. Os autores apresentam que as principais causas físicas são os desgastes da superfície e a fissuração. Dentre as causas químicas, citam-se as reações envolvendo a hidrólise e lixiviação dos componentes da pasta de cimento, reações de troca de fluidos agressivos com a pasta, assim como, reações envolvendo formação de produtos expansivos.

Dentre as causas de deterioração citados, na ETA em estudo destaca-se a presença de fissuração, de sedimentos decorrentes do processo de lixiviação do concreto, de corrosão das armaduras e dos desgastes de superfície.

Metha e Monteiro (1994) esclarecem que a lixiviação é um fenômeno patológico decorrente da ação gerada pela condensação dos vapores inferiores e infiltração de água sobre a parte superior do elemento estrutural. Quando esta água entra em contato com a pasta de cimento Portland, ela tende a hidrolisar os produtos que tem cálcio. Uma vez que a solução de contato atinja o equilíbrio químico, a hidrólise adicional da pasta de cimento vai parar. Entretanto, caso a presença de água seja contínua, ocorre a diluição da solução de contato, proporcionando, portanto, a continuação da hidrólise. Teoricamente, a hidrólise da pasta de cimento continua até que a maior parte do hidróxido de cálcio tenha sido retirada por lixiviação. Isto expõe os outros constituintes cimentícios à decomposição química. Por fim, o processo deixa para trás géis de sílica e alumina com pouca ou nenhuma resistência.

Além de causar a perda de resistência, muitas vezes o produto da lixiviação interage com o $\mathrm{CO}_{2}$ presente no ar resultando na precipitação de manchas brancas ou de estalactites de carbonato de cálcio na superfície, interferindo diretamente na estética das edificações.

Com relação à corrosão das armaduras do concreto armado, Ribeiro e Cunha (2013) destacam que o principal processo que ocorre nesses elementos é a corrosão eletroquímica, que consiste na transferência de elétrons, decorrente da diferença de potencial entre elementos, através de um eletrólito. Então, o processo de corrosão eletroquímica do aço, envolto pelo concreto, só ocorre com a presença de um eletrólito que, no caso, pode ser a água ou um ambiente com umidade relativa elevada. Ainda, no processo é necessário que haja oxigênio para permitir a formação da ferrugem.

A diferença de potencial entre pontos da barra de aço pode existir devido a diversos fatores, dentre os quais os autores citam: diferença de umidade, aeração, concentração salina, tensão no concreto e no aço.

Segundo Cascudo e Helene (1999), com relação aos sintomas da corrosão sabe-se que o mais comum é a presença de manchas de óxidos / hidróxidos de cor marrom avermelhadas na superfície de concreto. Porém, sabe-se que quando uma estrutura está danificada, a corrosão pode se apresentar sem nenhum sinal visível na superfície do concreto, de forma tal que a anomalia pode não só existir nas zonas que se mostram deterioradas, como também podem estar corroídas as redondezas situadas em partes sem sinal algum de danos externos visíveis.

Ribeiro e Cunha (2013) apresentam, ainda, que a corrosão resulta na formação de óxi-hidróxidos de ferro, que passam a ocupar no interior do concreto volume até dez vezes superior ao volume original do aço da armadura, podendo causar tensões internas maiores que $15 \mathrm{MPa}$. Dessa forma, iniciado o processo de corrosão, as armaduras oxidadas tendem a se expandir, devido às tensões de tração interna citadas, podendo provocar o rompimento do concreto do cobrimento e a consequente exposição das armaduras.

A influência da corrosão no concreto, com o surgimento de tensões internas, pode ser observada na imagem que segue.
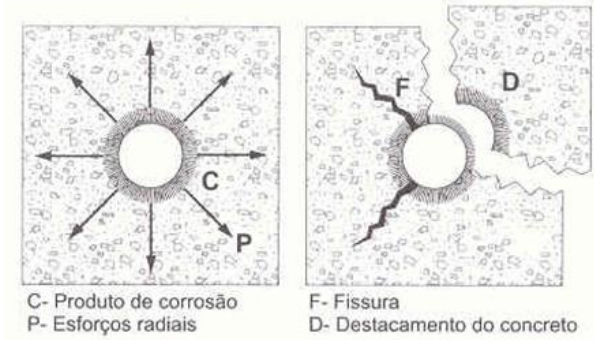

Figura 3: Tensões internas produzidas no concreto devido à corrosão da armadura. Fonte: Cascudo (1997). 
Então, observa-se que para a ocorrência dos principais meios de degradação do concreto, é necessária a presença de água, que pode aparecer a partir de uma infiltração através do elemento estrutural ou pela condensação de água nas superfícies expostas.

No caso das estações de tratamento de água, falhas no sistema de impermeabilização, a presença de fissuras e trincas e a existência de aberturas sem os corretos tratamentos de impermeabilização são os principais fatores que contribuem para o surgimento de manifestações patológicas no sistema.

Na figura que segue são apresentados registros fotográficos da ETA estudada, podendo ser observada a grande quantidade de manchas na superfície decorrentes da corrosão das armaduras e da lixiviação do concreto.
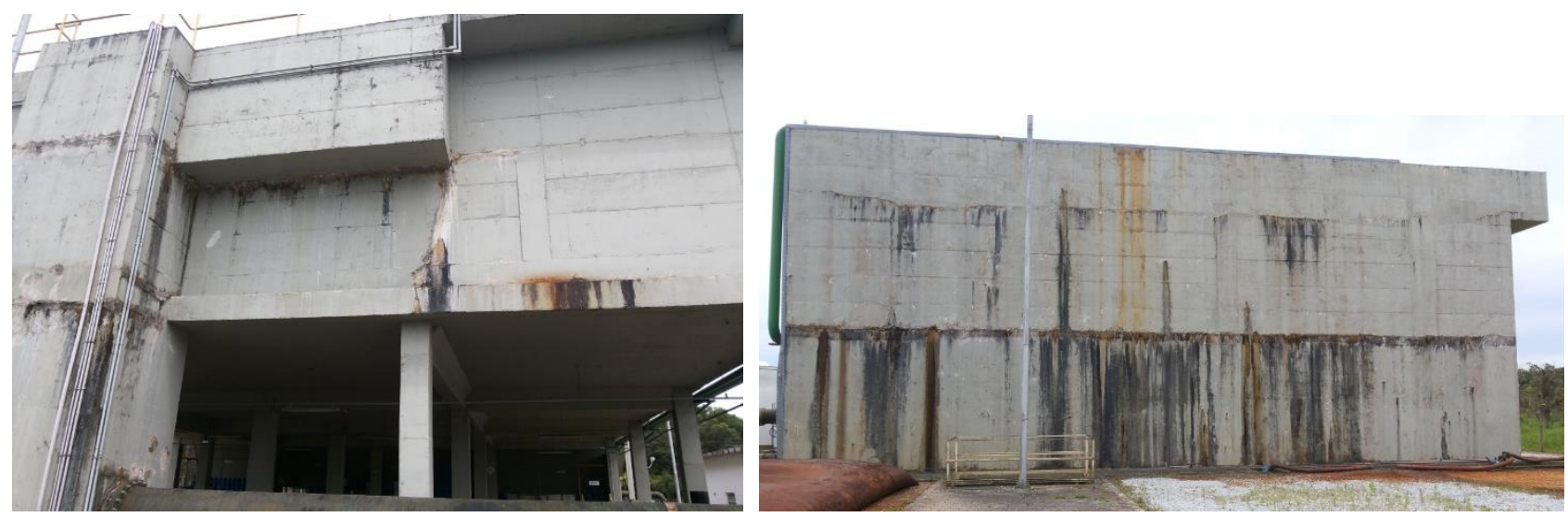

Figura 4: Manchas na superfície do concreto decorrentes da lixiviação do concreto e da corrosão das armaduras. Fonte: Os autores.

Da análise visual da ETA, foi verificado que a maior parte das infiltrações decorrem da grande quantidade de fissuras e trincas, com diferentes origens.

Segundo Carmona e Helene (1986), o concreto armado pode fissurar devido à atuação das cargas permanentes e acidentais, pela ação de recalques diferenciais, por ações resultantes de movimentação térmica, de retração ou de deformação lenta do concreto, reações químicas de expansão e/ou devido a presença de esforços decorrentes da retração plástica do concreto dentro das formas, restringido pela possível rigidez das armaduras. Ainda, falhas executivas podem contribuir para o processo de formação das fissuras.

Em análise das anomalias levantadas no local, observa-se que as situações mais avançadas são aquelas observadas em regiões de juntas construtivas das formas de execução dos elementos em concreto armado. As chamadas "juntas frias" ou juntas de concretagem tratam-se de falhas executivas decorrentes da ausência de tratamento adequado das interfaces do concreto nas etapas de concretagem. Tendo em vista as dimensões da edificação, com grandes paredes em concreto armado, a definição da correta sequência executiva de concretagem é essencial para que se atinja a qualidade esperada em projeto. Quando não atendida a boa prática da engenharia, surgem regiões suscetíveis ao aparecimento de anomalias, como o observado.

No caso da ETA em análise, as juntas de concretagem são observadas no sentido horizontal, ao longo de todo o entorno da construção, sendo que a infiltração por essas juntas frias permitiu o início do processo de lixiviação do concreto e a consequente corrosão das armaduras.

Na Figura 5 é possível observar as manifestações patológicas decorrentes das falhas executivas. 

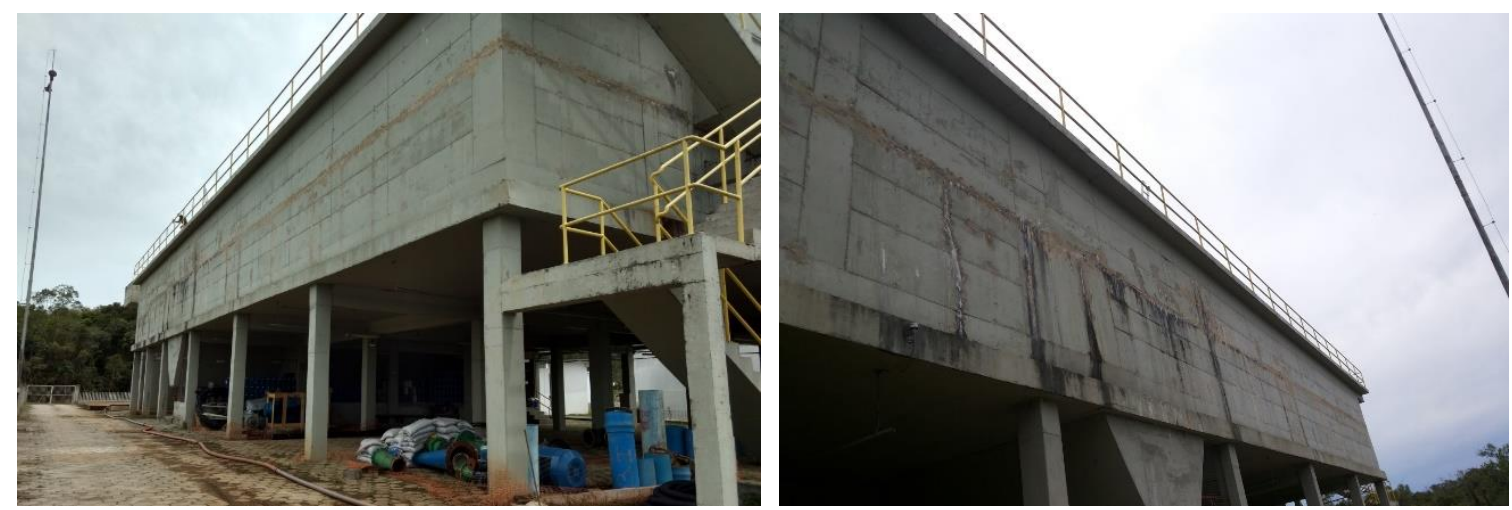

Figura 5: Presença de fissuras originadas pela falha executiva, com o surgimento das juntas de concretagem. Fonte: Os autores.

Além das fissuras decorrentes das falhas de concretagem, que tem como característica um alinhamento bem definido, foram observadas fissuras verticais nas paredes dos reservatórios da ETA, como pode ser observado na Figura 6.
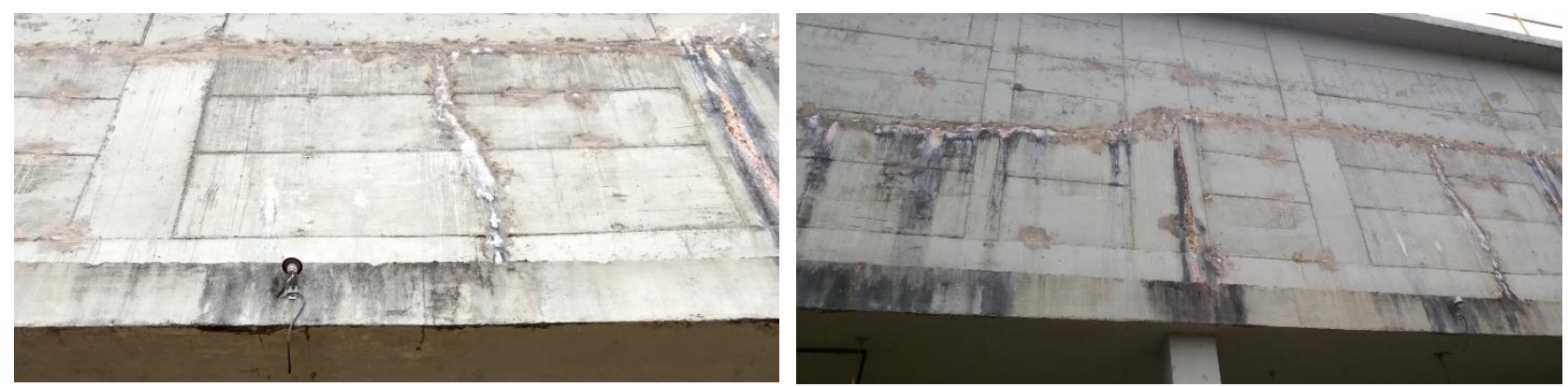

Figura 6: Fissuras verticais nas paredes dos reservatórios da ETA.

Fonte: Os autores.

Destaca-se que quando do dimensionamento de elementos estruturais de grande volume, além da análise da estrutura com base nos esforços solicitantes decorrentes das cargas de peso próprio dos elementos, equipamentos e da água, e carga acidentais de uso, devem ser analisados os efeitos agravantes dos esforços de coação.

Thomaz (2006) esclarece que fissuras de coação, em geral, se apresentam na direção vertical, em decorrência de tensões de tração decorrentes do impedimento de deslocamentos causados pelos gradientes internos de temperatura e de umidade, vinculados ao esfriamento rápido do concreto ou pela retração impedida no concreto.

Segundo apresentado por Falkner (apud Thomaz, 2006), essas fissuras ocorrem de 100 a 300 dias após a concretagem devido ao surgimento de tensões de tração causadas pela retração impedida do concreto, assim como pode ser visto no gráfico apresentado na Figura 7.

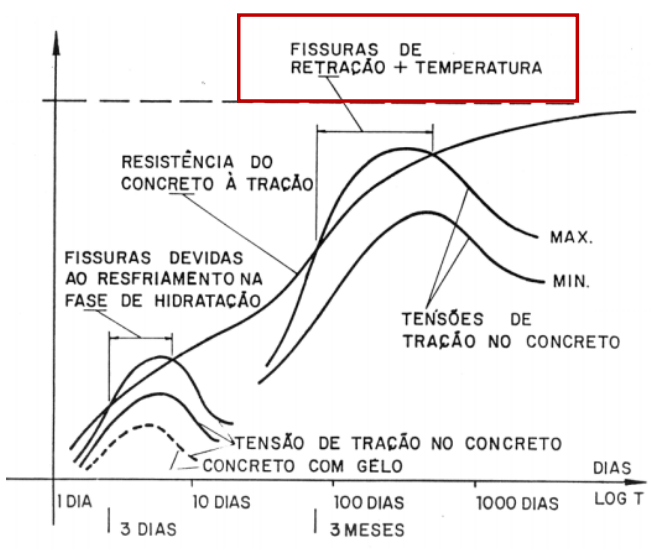

Figura 7: Fissuras de coação em estruturas de concreto.

Fonte: Thomaz (2003). 
Thomaz (2003) esclarece que a melhor maneira de evitar as tensões de coação é permitir a deformação da estrutura, com a adoção, por exemplo, de apoios móveis. No entanto, quando isso não é possível, como no caso das estruturas de estações de tratamento de água, essas fissuras podem ser controladas com o cálculo e detalhamento de armaduras com base no critério de H. Falkner, com uso do ábaco apresentado na Figura 8.
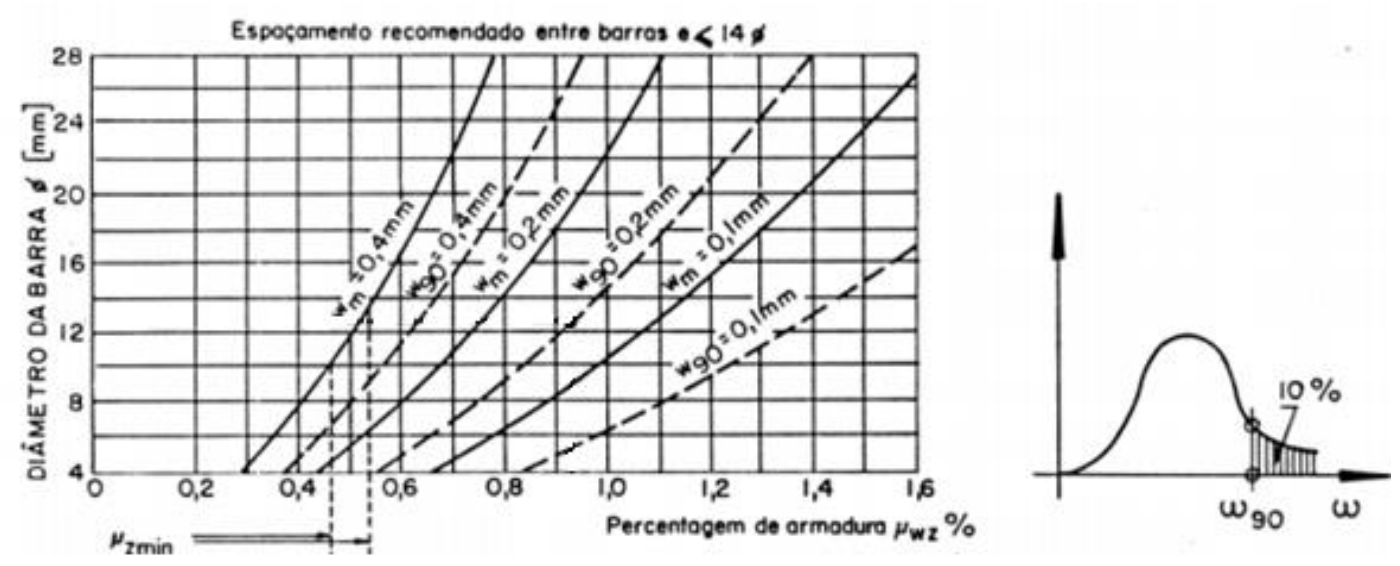

Figura 8: Ábaco de H. Falkner.

Fonte: Thomaz (2003).

O cálculo da armadura é dado pela seguinte fórmula:

$$
\mathrm{uzw}=\frac{\mathrm{A}_{\mathrm{s}}}{\mathrm{t} \cdot \mathrm{dw}}
$$

(Equação 1)

Onde se tem as variáveis descritas abaixo:

uzW = porcentagem da armadura para controle dos efeitos de coação.

$\mathrm{A}_{\mathrm{s}}=$ diâmetro da barra adotada. $\mathrm{t}=$ espaçamento entre as barras.

$\mathrm{d}_{\mathrm{w}}=\mathrm{u}+7 \phi$, com $\mathrm{u}$ igual ao cobrimento da armadura e $\phi$ o diâmetro.

Considerando o limite de abertura de fissuras recomendado pela norma para estruturas de estações de tratamento de água, igual a $2 \mathrm{~mm}$, e barras de $10 \mathrm{~mm}$ (adotado em projeto), tem-se, do Ábaco de Falkner uzw = 0,685. Portanto, aplicando esse valor na formulação indicada e cobrimento de $4 \mathrm{~cm}$ (definido em projeto), obteve-se um espaçamento $\mathrm{t}=10,8 \mathrm{~cm}$.

Destaca-se que para o cálculo foi adotado o cobrimento de $4 \mathrm{~cm}$, adotado em projeto, apesar de ser recomendado pela norma um cobrimento mínimo de $5 \mathrm{~cm}$ para estruturas de concreto armado de estações de tratamento de água.

Da análise do projeto estrutural, foi identificado que as paredes foram detalhadas com armadura de $10 \mathrm{~mm}$ a cada $15 \mathrm{~cm}$, espaçamento esse inferior ao obtido com os cálculos recomendados por Thomaz (2003) com base nos estudos de Falkner, o que justifica o surgimento das fissuras observadas.

Vale ressaltar que a área de aço adotada atende ao critério estabelecido em norma para a armadura das faces de vigas, indicado no item 17.3.5.2.3 Armadura de pele: “A mínima armadura lateral deve ser 0,10\% $\mathrm{A}_{\mathrm{c}, \text { alma }}$ em cada face da alma da viga e composta por barras de CA-50 ou CA-60, com espaçamento não maior que $20 \mathrm{~cm}$ e devidamente ancorada nos apoios.".

Porém, as paredes da ETA tratam-se de elementos estruturais com comportamento diferenciado tendo em vista os carregamentos atuantes, o grande volume de concreto e o consequente surgimento dos esforços de coação resultantes da retração do concreto. 
Portanto, em várias situações pode ser observado que as armaduras projetadas não atendem às recomendações para disposição das armaduras longitudinais em elementos de comportamento de viga parede, onde esta armadura deveria estar em intervalo maior ao longo da altura e não somente juntos às faces tracionadas.

Conclui-se, então, que a armadura de pele adotada não é suficiente para controle dos esforços resultantes, que provocaram a fissura vertical, decorrentes das componentes das ações verticais e demais efeitos combinados, como temperatura, retração, temperatura diferencial entre as faces e diferença de carga entre partes da estrutura nos processos de carga e descarga.

Ainda, foi observada a presença de fissuras, de lixiviação e de deposição de material decorrente da corrosão das armaduras nas paredes do chamado decantador, que consiste em elementos estruturais com abas inclinadas, como pode ser visto na Figura 9.
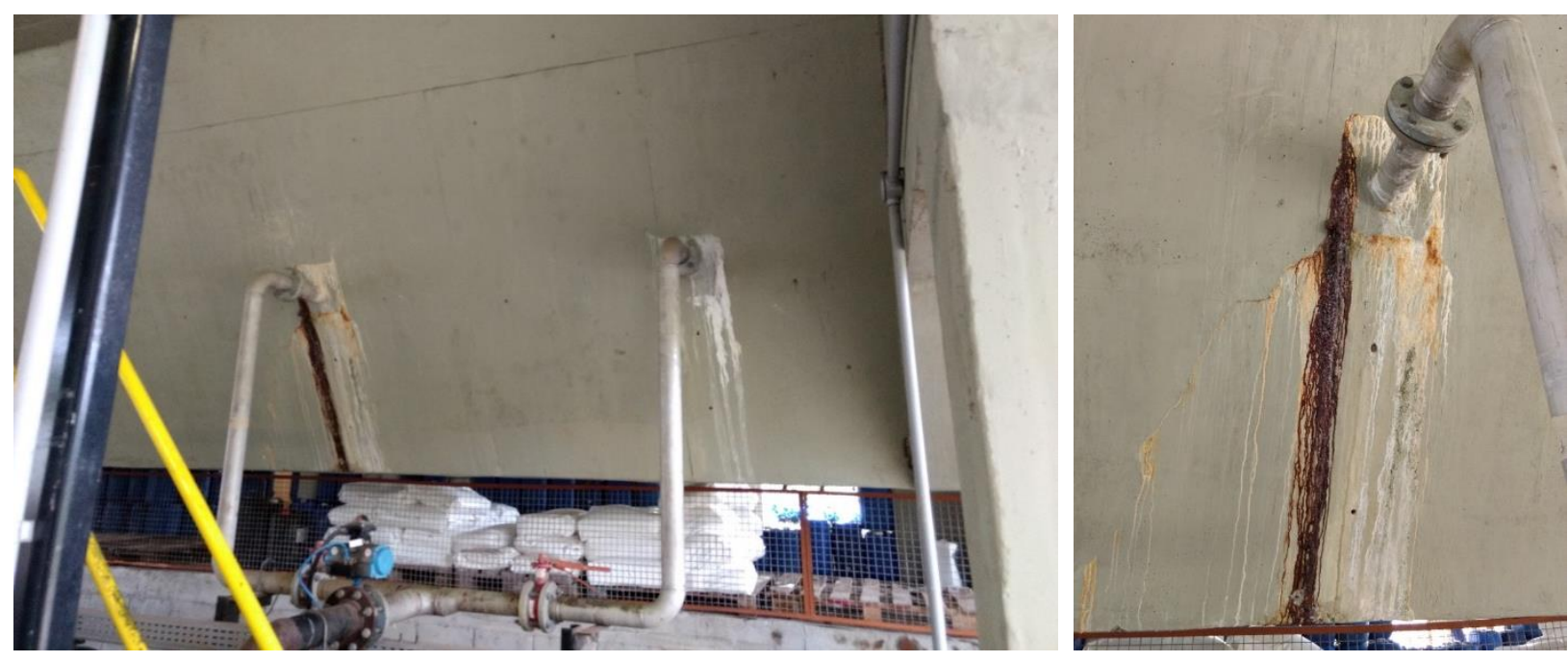

Figura 9: Manifestações patológicas na aba inclinada do decantador.

Fonte: Os autores.

Com a análise visual da região verificou-se um padrão de formato das fissuras na aba do decantador, indicado na Figura 10, sendo que todas tem sua origem da abertura da tubulação existente.

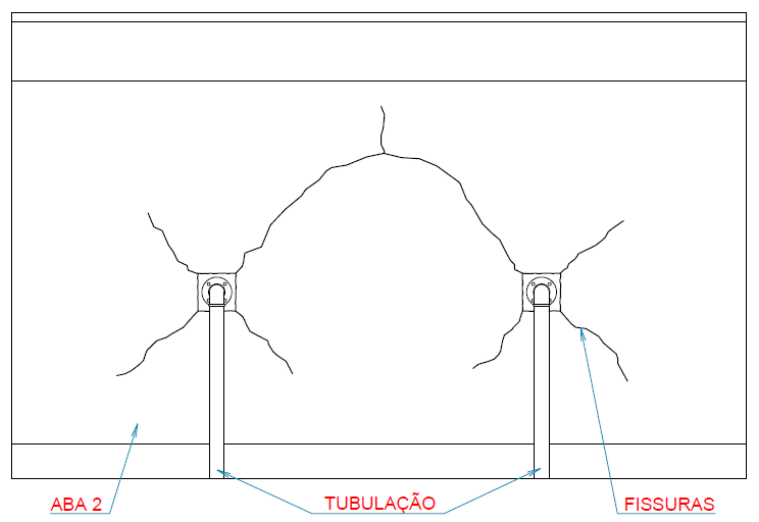

Figura 10: Padrão de formato das fissuras na aba do decantador.

Fonte: Os autores.

Observa-se que na região das tubulações foi prevista uma abertura quadrada, que consiste em uma geometria maior que a tubulação adotada. Portanto, entende-se que a parede do decantador foi pojetada com uma abertura genérica, a ser vedada após a instalação dos equipamentos. Dessa maneira, a concretagem da aba ocorreu com uma primeira fase, na qual foram deixadas aberturas quadradas, para posterior locação das tubulações e nova concretagem ou vedação dos espaços deixados. Na Figura 11 é apresentada uma imagem onde fica clara a concretagem em duas etapas. 


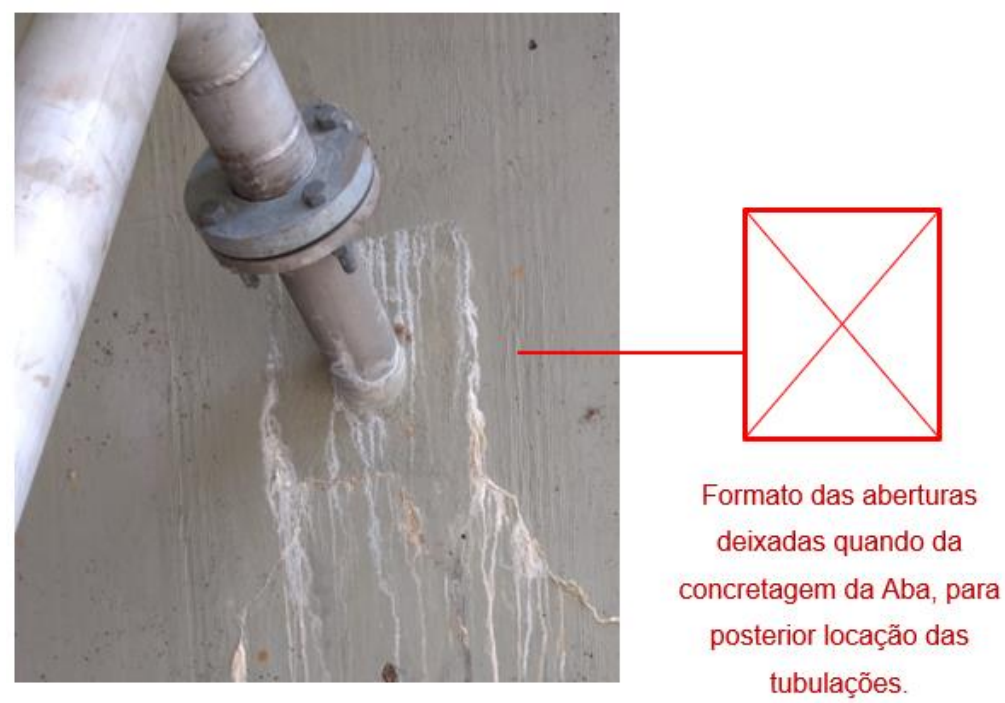

Figura 11: Formato das aberturas para as tubulações da aba do decantador.

Fonte: Os autores.

Considerando o aparecimento de fissuras nessa região, verifica-se que não houve o adequado tratamento da interface, resultando na ausência de aderência entre as partes. Ainda, pode ser observado em projeto que não foram previstas armaduras de reforço nas aberturas criadas para acomodação das tubulações.

Segundo apresentado por Thomaz (2003), paredes de concreto com muitas aberturas são suscetíveis ao aparecimento de fissuras nos cantos dessas aberturas, devido à retração térmica do concreto durante o processo de hidratação e cura e à retração hidráulica associada à variação de temperatura que geram tensões de tração junto aos cantos das aberturas. Quando não há o correto tratamento da região, essas tensões tendem a gerar fissuras no concreto, com o padrão observado na Aba do decantador da ETA am análise.

Segundo apresentado no item 21.3.2 da norma ABNT NBR 6118/2014, em paredes "quando as aberturas se localizarem em regiões pouco solicitadas e não modificarem significativamente o funcionamento do elemento estrutural, basta detalhar a armadura de compatibilização da abertura com o conjunto."

Portanto, para aberturas como as observadas na parede do decantador da ETA deve ser prevista uma armadura capaz de controlar as tensões que se concentram na região das aberturas, com o detalhamento de barras conforme o padrão apresentado na Figura 12, onde as armaduras são indicadas em azul.

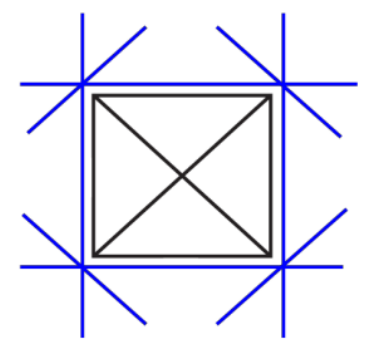

Figura 12: Detalhamento genérico das armaduras de aberturas em elementos de concreto armado. Fonte: Adaptado da ABNT NBR 6118/2014.

Ainda, nas vigas transversais às paredes inclinadas do decantador foi observada a presença de fissuras, como a indicada na Figura 13. 

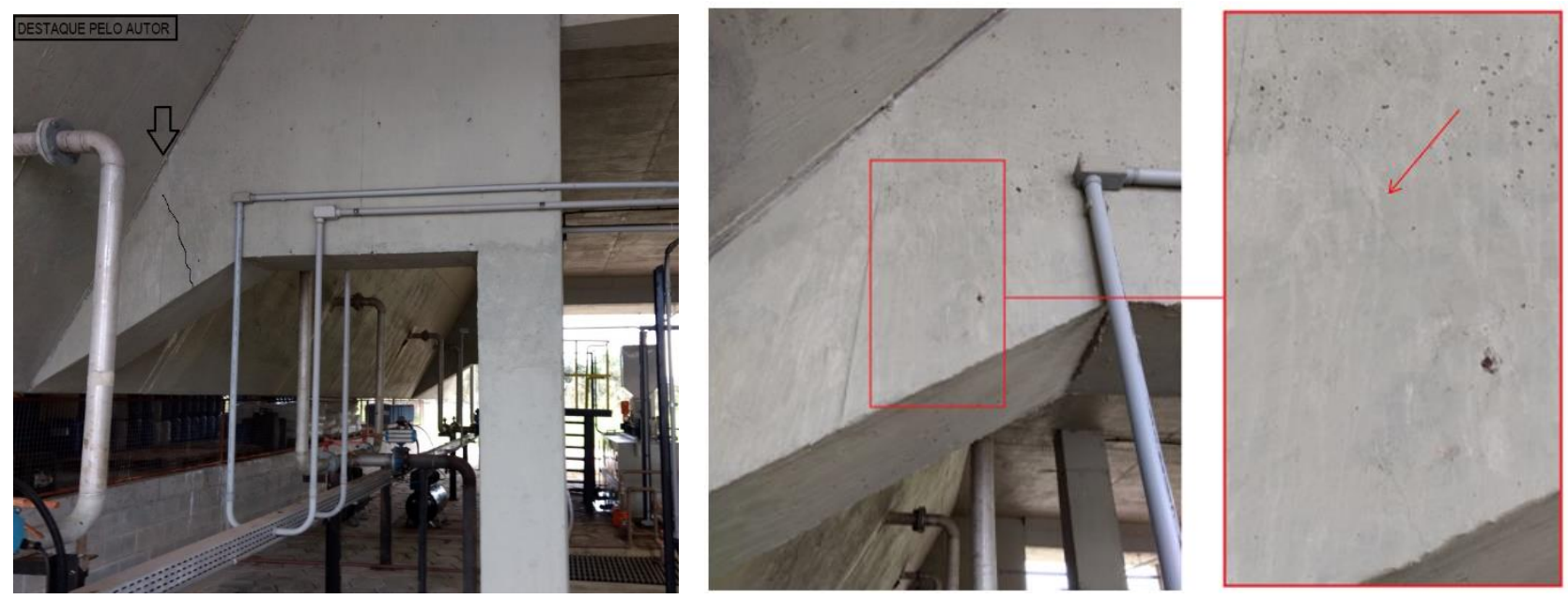

Figura 13: Fissuras nas vigas transversais à aba do decantador.

Fonte: Os autores.

Da análise visual da estrutura e do projeto estrutural, verificou-se que as mesmas decorrem pela influência de parte da carga da parede (nomeada no projeto estrutural existente como cortina vazada) que se concentra sobre a laje que se apoia nas vigas afetadas.

Na Figura 14 é apresentado um trecho do projeto com a indicação da parede que se apoia na laje L6.
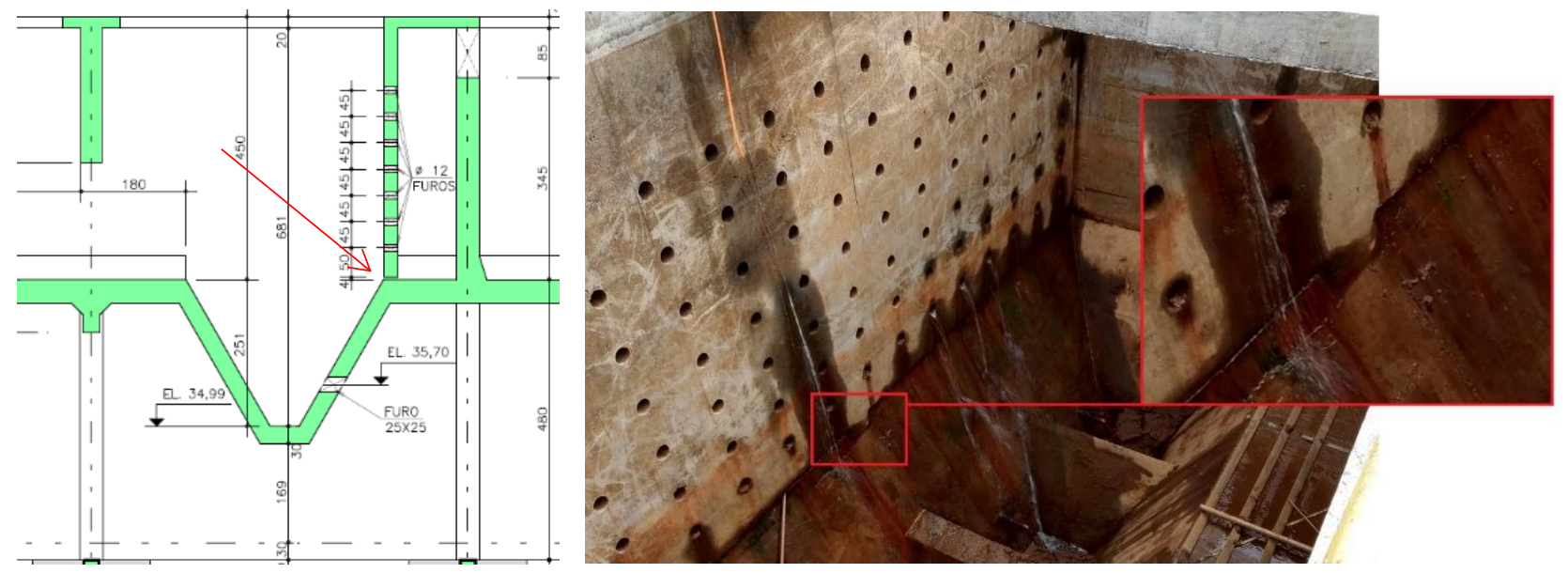

Figura 14: Indicação da parede que se apoia na parede do fundo da região do decantador - projeto e estrutura real. Fonte: Os autores.

Considerando as fissuras observadas nas vigas V1 e V2 e da análise do detalhamento das armaduras da cortina vazada, foi possível concluir que as vigas estavam sofrendo solicitações superiores às previstas, decorrentes de parte da carga da cortina vazada.

\section{CONSIDERAÇÕES SOBRE A PREVENÇÃO DE MANIFESTAÇÕES PATOLÓGICAS EM ETAS}

Das informações apresentadas no presente artigo, observa-se que os problemas existentes na estação de tratamento de água decorrem de diferentes origens, sendo observadas manifestações vinculadas com origem em projeto e também dos processos executivos.

Para melhor entendimento dos dados apresentados e resumo orientativo aos projetistas e executores da área, são listados e descritos os procedimentos que podem ser executados a fim de minimizar as manifestações patológicas em estações de tratamento de água, levando em consideração os dados observados no estudo de caso apresentado no presente documento. 
- Tratamento das juntas concretagem.

A presença de elementos de grandes dimensões nas ETAs cria a necessidade de concretagem em etapas, sendo que, em alguns casos, é necessário interromper a concretagem de um elemento para posterior continuidade. Esse procedimento deve ser evitado sempre que possível, com um adequado planejamento das cargas de concreto. Quando for necessária a interrupção do lançamento do concreto e, assim, formar-se uma junta de concretagem, alguns procedimentos devem ser adotados.

Antes de reiniciar o lançamento, deve ser removida a nata que se forma sobre a superfície do concreto e agregados soltos. A garantia de aderência pode ser dada com a criação de um substrato rugoso, obtido com o apicoamento de toda a superfície de interface entre etapas de concretagem. Na sequência, deve ser feita a limpeza superficial da junta, removendo-se toda a sujidade presente.

- Detalhamento adequado das armaduras das paredes

Elementos estruturais que compõem reservatórios são suscetiveis ao surgimento de fissuras decorrentes dos impedimentos gerados aos deslocamentos que surgem com os efeitos de temperatura, retração e fluência do concreto. Dessa forma, o correto detalhamento das armaduras é essencial para se minimizar o surgimento de tensões de tração excessivas e a consequente fissuração do concreto. Thomaz (2003) apresenta um procedimento de cálculo de armaduras de controle dos esforços de coação baseado no modelo de Falkner, sendo recomendado o uso de tal procedimento a fim de garantir um adequado detalhamento das armaduras.

Problemas vinculados à falhas estruturais podem ser minimizados com o desenvolvimento de modelos computacionais mais avançados, como é o caso dos modelos elaborados em elementos finitos de placas. Essa solução permite analisar de forma mais precisa o encaminhamento das cargas nas estruturas e, aliado ao bom conhecimento sobre o comportamento do concreto armado e de detalhamento das armaduras, permite se obter um projeto estrutural mais eficiente.

\section{Tratamento das aberturas}

Tendo em vista a necessidade de passagens de tubulações e equipamentos que fazem parte do sistema de tratamento de água por elementos estruturais, destaca-se a necessidade de que sejam tomados cuidados especiais no detalhamento das armaduras nessas regiões.

Publicações como as apresentadas por Fusco (1995), Thomaz (2003), Leonhardt e Moning (1978) são algumas das bibliografias disponíveis que contribuem para uma melhor solução no detalhamento das estruturas de concreto armado.

\section{- Definição dos materiais}

Por se tratarem de estruturas especiais, submetidas à ações de agentes químicos e em presença constante de água, as estações de tratamento de água devem ser projetadas com materiais específicos para essa aplicação. Atualmente, não é disponível no meio técnico uma norma técnica nacional que aborde recomendações para estruturas de concreto armado. No entanto, a Copasa disponibiliza a Norma Técnica T 175, em sua $3^{\text {a }}$ revisão, datada de maio de 2018, na qual são apresentadas recomendações para o projeto e execução de estruturas de concreto armado para obras de saneamento.

Dentre as recomendações apresentadas nessa norma técnica, para estações de tratamento de água, destacam-se as seguintes: adoção de concreto com resistência característica à compressão $\left(\mathrm{f}_{\mathrm{ck}}\right)$ mínima de $35 \mathrm{MPa}$; relação a/c $\leq 0,50$; cobrimento mínimo das armaduras de $3,5 \mathrm{~cm}$ para lajes de fundo, 4,0 cm para paredes, vigas e pilares, 4,5 cm para vigas superiores e face inferior da laje de cobertura; limite de abertura de fissuras de $0,15 \mathrm{~mm}$ para elementos em concreto não revestidos. Outras informações podem ser vistas na publicação, que é disponibilizada gratuitamente no site da companhia.

\section{CONSIDERAÇÕES FINAIS}

Segundo apresentado por Campagner et al (2007), os custos de recuperação ou reforço estrutural de uma obra de estrutura para o saneamento podem chegar entre $50 \%$ a $150 \%$ do custo total da obra nova. Então, entende-se que a elaboração de projetos de maior qualidade, com um maior nível de detalhamento, é essencial para que sejam obtidas construções com maior desempenho e durabilidade. Ainda, a contratação de mão de obra especializada, que siga as normativas vigentes, assim como, a boa prática da engenharia civil, contribui para a melhoria da qualidade das obras executadas.

Nas obras de estações de tratamento de água destaca-se a necessidade de que seja dada atenção especial aos mecanismos que possam originar fissuras e trincas no concreto, dentre os quais citam-se as juntas de concretagem, a presença de 
fissuras por retração do concreto ou devido à efeitos térmicos nos grandes elementos e fragilizações da estrutura decorrentes de aberturas e cargas concentradas.

Isso se deve ao fato de que a percolação da água pelos elementos estruturais permite o surgimento de processos de degradação dos materiais, como a lixiviação do concreto e a corrosão das armaduras, os quais reduzem sensivelmente a durabilidade das construções, podendo, em alguns casos, afetar a segurança das mesmas.

Quando da ocorrência dos mecanismos de fissuração no sistema estrutural, como no estudo de caso do presente artigo, no qual foi observado o surgimento de fissuras que atravessavam os elementos estruturais, uma das soluções consiste na injeção das fissuras com uso de gel de poliuretano, que consistente em um selante flexível, e manutenção do sistema de impermeabilização com uso de produtos cristalizantes, que garantem a selagem de pequenas aberturas nas estruturas de concreto.

Por fim, o presente artigo teve como objetivo orientar os profissionais da área sobre as principais manifestações patológicas observadas em obras de saneamento, permitindo que sejam tomadas ações preventivas que possam minimizar os problemas observados e, portanto, contribuindo para a construção de obras de maior durabilidade e desempenho.

\section{REFERÊNCIAS}

ASSOCIAÇÃO BRASILEIRA DE NORMAS TÉCNICAS. NBR 6118: Projeto de estruturas de concreto Procedimento. Rio de Janeiro, 2014.

CAMPANER, S. K.; CARVALHO, M. J. H.; LOBO, A. V. L. Revista Concreto e Construções: Obras de concreto para o Saneamento Ambiental: cuidando do meio ambiente e da saúde pública. $47^{\text {a }}$ Ed. São Paulo: IBRACON, 2007.

CARMONA, A. F.; HELENE, P. R. L. Fissuração das peças de concreto armado e corrosão das armaduras. Seminário Nacional de Corrosão na Construção Civil, Rio de Janeiro: ABRACO, 1986.

CASCUDO, O. O Controle da Corrosão de Armaduras em Concreto. Inspeções e técnicas eletroquímicas. São Paulo: Pini, 1997.

CASCUDO, O.; HELENE, P. Comportamento Mecánico del Hormigon de Recubrimento frente a los Produtos de Corrosión de las Armaduras. Hormigón Y Acero, Barcelona, n. 214, p. 75-83, dez. 1999.

IAPAR. Cartas climáticas do Paraná. Disponível em:

http://www.iapar.br/modules/conteudo/conteudo.php?conteudo=604. Acesso em: 30 de junho de 2017.

FUSCO, Péricles Brasilience. Técnica de armas as estruturas de concreto. São Paulo: Pini, 1995.

MEHTA, P. K.; MONTEIRO, P. J. M. Concreto. Microestrutura, propriedades e materiais. $3^{\text {a }}$ edição. São Paulo: IBRACON, 2008.

PÁDUA, Valter Lúcio de. Abastecimento de água para consumo humano. Belo Horizonte: UFMG, 2006.

RIBEIRO, D. V.; CUNHA, M. P. T. Corrosão em estruturas de concreto Armado: teoria, controle e métodos de análise: Capítulo 6. $1^{\text {a }}$ edição. Rio de Janeiro: Elsevier, 2014.

THOMAZ, Eduardo Christo Silveira. Fissuração - 168 Casos Reais. Rio de Janeiro, 2003. Disponível em: <http://aquarius.ime.eb.br/ webde2/prof/ethomaz/fissuracao/ >. Acesso em: 18 de dezembro de 2019.

THOMAZ, Eduardo Christo Silveira. Fissuras em Reservatórios de Concreto Armado: Conceitos e Teoria (apresentação em slides). Rio de Janeiro, 2006. Disponível em:

< http://aquarius.ime.eb.br/ webde2/prof/ethomaz/reservat/fissuracao_reservat.pdf>. Acesso em: 18 de dezembro de 2019. 